Studies in African Linguistics

Volume 25, Number 1, Spring 1996

\title{
[ATR] HARMONY IN TURKANA
}

\author{
Manuela Noske \\ University of California, Davis
}

This paper analyzes the [ATR] harmony system of Turkana (Eastern Nilotic). The principal claim made in this paper is that Turkana provides evidence for an underlying ternary contrast in the feature [ATR]. This claim is based on the observation that some suffixes alternate in [ATR] in agreement with a preceding root, while other suffixes surface as either [+ATR] or [-ATR], regardless of the context in which they occur. The claim that non-alternating suffixes are specified for [ATR] is supported by the fact that they cause regressive assimilation: a [-ATR] root surfaces as [+ATR] if followed by a [+ATR] suffix; a [+ATR] mid vowel root surfaces as [-ATR] if followed by a [-ATR] suffix. Turkana thus provides evidence that the feature [ATR] is ternary with the three values [+ATR], [-ATR] and [()ATR].

\section{Introduction*}

This paper presents a detailed description and analysis of the [Advanced Tongue Root] ([ATR]) harmony system of Turkana, an Eastern Nilotic language, spoken in Kenya. ${ }^{1}$ The principal claim of this paper is that Turkana presents evidence for an underlying ternary contrast in the feature [ATR]. This assumption is based on the observation that some suffixes alternate in this feature in agreement with a preceding root, while other suffixes surface as either [+ATR] or [-ATR] and are thus invariant, regardless of the context in which they occur. Non-altemating suffixes do not form a separate class in terms of their morphological properties; they attach

\footnotetext{
* I would like to thank Gerrit Dimmendaal for his help in gathering and analyzing the Turkana data and John Goldsmith for commenting on earlier versions of this work.

1 Together with Ateso, Karimojong, Jie, Dodos, Toposa and Nyangatom, Turkana forms the Teso-Turkana cluster of Eastern Nilotic (Nilo-Saharan) [Greenberg 1966, Vossen 1982]. The data used in this description are from field notes that I collected in Kenya in 1986 and 1988 and from Dimmendaal's [1983] grammar of the language.
} 
both to stems and to words, and inside as well as outside alternating suffixes and, therefore, cannot be correlated with a different level or stratum of the grammar. I propose that non-alternating suffixes are specified as either [+ATR] or [-ATR], while alternating suffixes are unspecified for this feature. The claim that nonalternating suffixes are specified for [ATR] is supported by the fact that they cause regressive assimilation: a [-ATR] root surfaces as [+ATR] if followed by a [+ATR] suffix; a [+ATR] mid vowel root surfaces as [-ATR] if followed by a [-ATR] suffix.

(1)

$\underline{\text { Roots }}$

$\begin{array}{lll}\text { [+ATR] } & \text { /-gol/ 'close' } \\ & \text { /-rem/ 'spear' } \\ & \text { /-buk/ 'pour' } \\ \text { [-ATR] } & \text { /-dok/ 'climb' } \\ & \text { /-gyel/ 'buy' } \\ & \text { /-dok/ 'hide' }\end{array}$

\begin{tabular}{|c|c|c|}
\hline \multicolumn{3}{|c|}{ Suffixes } \\
\hline $\begin{array}{c}{[+\mathrm{ATR}]} \\
\mid-\mathrm{e} /\end{array}$ & $\begin{array}{c}{[-\mathrm{ATR}]} \\
\mid-\mathrm{r} \varepsilon /\end{array}$ & $\begin{array}{c}\text { unspecified } \\
\text { /-Un/ }\end{array}$ \\
\hline $\begin{array}{l}\text { [e-gol-e] } \\
{[\text { e-rem-e] }} \\
{[\text { e-buk-e] }}\end{array}$ & $\begin{array}{l}\text { [a-gol- } \varepsilon-\mathrm{r} \varepsilon] \\
\text { [a-rem- } \varepsilon-\mathrm{r} \varepsilon] \\
\text { [a-buk- } \varepsilon-\mathrm{r} \varepsilon]\end{array}$ & $\begin{array}{l}\text { [a-gol-un] } \\
\text { [a-rem-un] } \\
\text { [a-buk-un] }\end{array}$ \\
\hline $\begin{array}{l}\text { [e-dok-e] } \\
\text { [e-gyel-e] } \\
{[\text { e-duk-e] }}\end{array}$ & $\begin{array}{l}\text { [a-dok- } \varepsilon-\mathrm{r} \varepsilon] \\
\text { [a-gyel- } \varepsilon-\mathrm{r} \varepsilon] \\
{[\mathrm{a}-\mathrm{d} u \mathrm{k}-\varepsilon-\mathrm{r} \varepsilon]}\end{array}$ & $\begin{array}{l}\text { [a-dok-un] } \\
\text { [a-gyel-un] } \\
\text { [a-duk-un] }\end{array}$ \\
\hline
\end{tabular}

By showing that the feature [ATR] is used in a temary fashion, the present study contributes to the discussion on underspecification in phonological theory. Specifically, it provides evidence against the assumption, known as radical underspecification theory, that only one value of every feature is specified underlyingly, while the complementary value is filled in by a redundancy rule [Kiparsky 1982, 1985; Archangeli 1984, 1988; Archangeli and Pulleyblank 1986]. Although a popular theory in the 1980 s, several studies have since then questioned its empirical and theoretical foundation [Steriade 1987, 1995; Clements 1988, Mohanan 1991]. The result is that the theory of radical underspecification must now be considered defunct, so that the question of what features are present and what features are absent underlyingly is again open to investigation.

The development of Optimality Theory [McCarthy and Prince 1993, Prince and Smolensky 1993] has lead to a renewed interest in this topic. Itô, Mester, and Padgett [1995] have recently claimed that underspecification is not a requirement on input forms and so is unnecessary, since the choice of output form depends on the constraint ranking alone. In evaluating their proposal, however, it must be kept in mind that they focus exclusively on the surface distribution of the feature [voice] in Japanese, without taking morphophonological altemations into account. A different conclusion emerges when the investigation is extended to that area of phonology. Inkelas [1994], for example, claims that underspecification is necessary even in Optimality Theory to capture the different alternation patterns found in languages. A similar observation has previously been made by Ringen [1989] and Noske [1990, 1991a, 1993] within a rule-based approach to phonology. Since the fundamental insight of this paper, namely that languages make use of a ternary 
contrast in features underlyingly, appears to be independent of the question of whether the phonological grammar of a language is understood in terms of rules or constraints, the present study relies on rules rather than constraints in its analysis.

The paper is structured as follows. Section 2 introduces the vowel inventory of Turkana together with those realization rules that yield information about their surface [ATR] specification. Section 3 presents the non-alternating [+ATR] and [-ATR] suffixes of Turkana, while section 4 is concerned with the distribution of the features [+ATR] and [low]. Section 5, finally, describes and analyzes the role glides play in the harmony system of Turkana. Section 6 concludes.

\section{Turkana Vowel Inventory and Realization Rules}

Turkana distinguishes nine vowel qualities. Vowel length is distinctive, raising the number of underlying vowels to eighteen.

(2) The underlying vowel inventory of Turkana

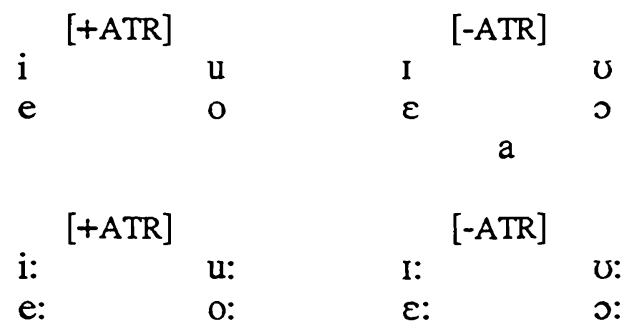

a:

The feature [ATR] serves to separate the non-low vowels in Turkana into two sets. That the feature [ATR] is distinctive is evidenced by the following sets of minimal pairs.
a. [akiduk] 'to build'
b. [akirip] 'to skim off'
c. [akimor] 'to insult, beat'
[akıduk] 'to hide'
d. [akiger] 'to harvest'
[akırip] 'to investigate, peep'
e. [akime] 'to lick'
[akımor] 'to share food'
f. [akimor] 'to insult, beat'
[akiger] 'to tattoo, cut'
g. [akirem] 'to pierce'
[akıme] 'to send'
[akimar] 'to count'
[akıram] 'to beat'

As concems the realization of the feature [ATR], both vowel height and stress need to be taken into account. In general, [ATR] distinctions are more clearly audible in mid than in high vowels. Among high vowels, the difference between [+ATR] and [-ATR] is easier to perceive in back vowels than in front vowels. 
Regarding the realization of the feature [ATR] in stressed syllables, I find the [+ATR] and [-ATR] vowels of Turkana auditorily quite close to the tense and lax vowels of English and German. That is, the [+ATR] vowel /i/ is similar in quality to the tense vowel in English beat, while its [-ATR] counterpart /I/ resembles the lax vowel in bit, without the length distinction that accompanies these vowels in English. Likewise, the [+ATR] vowel [u] and the [-ATR] vowel [U] resemble the tense and lax vowels in English boot and put, respectively. The same relationship between [ATR] and tenseness holds for mid vowels. The [+ATR] vowel /e/ resembles the tense mid vowel in German Beet, the [-ATR] vowel / $\varepsilon /$ the lax vowel in German Bett. Turkana /o/ and /o/ are realized like the vowels in German Boot and Gott, respectively, without the concomitant length difference. The only difference between the vowels of Turkana and the vowels in English or German lies in their voice quality. I find that the [-ATR] vowels of Turkana sound "choked", back vowels more so than front vowels, but I did not notice a breathy voice quality with [+ATR] vowels that is reported by some authors who have worked on vowel harmony in Eastern Nilotic.

Short high front vowels in unstressed syllables tend to neutralize to schwa in fluent speech. (In fact, they are often deleted in a two-sided open syllable in fast speech.) In careful pronunciation, it is nevertheless possible to perceive a distinction between [+ATR] and [-ATR] high front vowels even in unstressed syllables. However, I have the impression that this difference involves vowel height rather than tongue root position, i.e., I perceive a [+ATR] high front vowel in unstressed syllables as centralized [i], and a [-ATR] high front vowel as further reduced to schwa [ə]. I transcribe these vowels respectively as [i] and [I] through-out, thus making no distinction between stressed and unstressed positions. No such drastic differences in the realization of the feature [ATR] can be observed in the remaining vowels.

There is a certain amount of evidence from the realization of consonants that [-ATR] vowels are produced with an active retraction of the tongue root. Dimmendaal [1983] reports that the voiceless velar stop $/ \mathrm{k} /$ is realized at a uvular place of articulation ([q]) if followed or preceded by the vowels $/ a /, / o /$ or $/ \mathrm{o} /$ in the same syllable, as shown in (4). It can surface as a velar or uvular fricative if surrounded by these vowels, as illustrated in (5) below; the fricative can be either voiced or voiceless. 


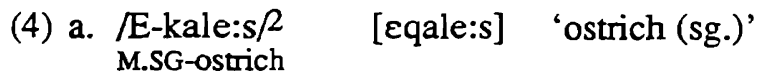
b. /a-koro/
F.SG-hunger
[aqoro] 'hunger'
c. /a-kolon/
F.SG-sun
[aqolon] 'sun (sg.)'

(5) a. /a-bokok/

F.SG-turtle

[aboyoq] 'turtle (sg.)'
b. /a-kamu/
F.SG-dry season
[ayamu] 'dry season (sg.)'
c. /a-koko/

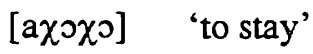

Dimmendaal [1983] draws a connection between "uvularization" of $/ \mathrm{k} /$ and the [-ATR] quality of the vowels $/ a /$ and $/ o /$, which leaves unexplained why this process also takes place if $/ \mathrm{k} /$ is tauto-syllabic with the [+ATR] vowel $/ 0 / . / \mathrm{k} /$ is often pharyngealized $\left(\left[\mathrm{k}^{\mathrm{S}}\right]\right)$ in the coda if preceded by the vowels $/ \mathrm{a} /$ and $/ \mathrm{o} /$, while no pharyngealization occurs after /o/. This confirms to some degree Dimmendaal's assumption that there is a connection between the realization of the velar stop $/ \mathrm{k} /$ and the $[-A T R]$ quality of the surrounding vowels.
(6)
a. /na-kıma-k/
F.PL-old woman-PL
[ gakımak ${ }^{\S}$ 'old woman (pl.)'
b. /a-kI-dok $\beta$
[akıdok $\left.{ }^{\S}\right]$ 'to climb'

\begin{abstract}
2 Non-low prefixes and suffixes that are unspecified for [ATR] are represented with capital letters in underlying representation. Roots and dominant [+ATR] and [-ATR] suffixes are represented with [+ATR] and [-ATR] vowels. Low vowels in prefixes, roots, and the elative suffix /-ar/ do not alternate in tongue root position and so are symbolized by /a/; low vowels in the remaining suffixes, by contrast, alternate and so are represented by capital letters.

The following abbreviations are used throughout the paper.

$\begin{array}{llllllll}\text { A } & \text { aspect } & \mathrm{e} & \text { epenthetic } \sigma & \text { HAB } & \text { habitual } & \text { PL } & \text { plural } \\ \text { AG } & \text { agent } & \text { EL } & \text { elative } & \text { INF } & \text { infinitive } & \text { SG } & \text { singular } \\ \text { AL } & \text { allative } & \text { F } & \text { feminine } & \text { INST } & \text { instrumental } & \text { SUBJ } & \text { subjunctive } \\ \text { CAUS } & \text { causative } & \text { GER } & \text { gerund } & \text { M } & \text { masculine } & \text { V } & \text { voice } \\ \text { DAT } & \text { dative } & & & & & & \end{array}$

$3 /-\mathrm{kI}-/$ is an epenthetic syllable that is inserted between the infinitive prefix /a-/ and verb roots of class 1 , if the root is monomoraic (cf. [Noske 1991b]).
\end{abstract}


The fact that $/ \mathrm{k} /$ is pharyngealized after the [-ATR] vowels $/ \mathrm{a} /$ and $/ \mathrm{o} /$ suggests that these vowels are produced with an active retraction of the tongue root which results in a smaller pharyngeal cavity, pharyngealization thus being a co-articulation effect. Pharyngealization will not be indicated in the transcriptions which are broad, unless indicated otherwise.

\section{Vowel Harmony}

Turkana has vowel harmony of the cross-height type, i.e., each [+ATR] non-low vowel is paired with a [-ATR] vowel of the same height, the [+ATR] variant occurring in a [+ATR], the [-ATR] variant in a [-ATR] context. Non-low vowels from opposite sets are ordinarily excluded from appearing in the same morpheme, as shown by the forms in (7). These examples suggest that [ATR] is a morphemelevel feature which is floating in underlying representation.
(7) a. /E-lukutuj/
[elukutuj] 'wild cat (sg.)'
b. /a-purukuc/ [apurukut]] 'joint of arm or knee (sg.)'
c. /na-kı:ñIr/ [nakı:ñIr] 'sweat'
F.PL-sweat
d. $\underset{\text { M.SG-charm }}{\text { E-risik/ }}$ [erizik] 'anti-witchcraft charm (sg.)'
$\underset{\text { e. }}{\text { F.SG-sun }}$ [aqolon] 'sun (sg.)'
f. /a-koro/ [aqoro] 'hunger'

The examples in (7) also demonstrate that non-low prefix vowels agree with a following root in tongue root position. Since their [ATR] specification is predictable through context, I consider prefixes unspecified for this feature underlyingly.

Turkana suffixes either agree with the preceding root in [ATR] or are invariantly [+ATR] and cause regressive assimilation. The examples in (8) and (9) illustrate the first group of suffixes which harmonize with a preceding root. 
(8) a. /a-k-Ilrp-Un-I/4 [akılrpun] 'to pray this way'

INF-e-beg-AL-?

b. /a-limw-Un-I/ [alimwun] 'to tell'

INF-tell-AL-?

c. /a-dok-Un-I/ [adokun] 'to climb down'

d. /a-gol-Un-I/ [agolun] 'to close in'

INF-close-AL-?

(9) a. I'a-kuñ-In/ [nakuñm] 'knee (pl.)'

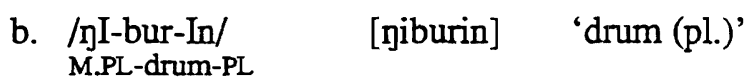

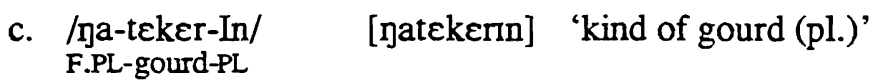

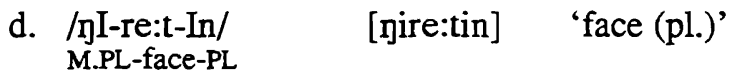

If several unspecified suffixes occur, all agree with the root in the feature [ATR].

(10)
a. /a-tam-Un-It/
[atamunit] 'I remember (it)'
b. /E-dit-E-Un-It/
[عditeunt] 'it becomes smaller'
c. /E-mo-n-Un-It/
3.SG-be hot-SG-AL-A
[emonunit] 'it becomes hotter'

As these suffixes alternate regularly in agreement with a preceding morpheme, I assume that they are unspecified for [ATR] underlyingly and receive a specification through spreading.

4 The suffix /-I/ attaches to verbs in the infinitive that have been expanded with one of the following suffixes: the habitual marker /-e:n/, the allative suffix /-Un/, the elative suffix /-ar/, and the dative marker /-AkIn/. Dimmendaal [1983:108] notes that/-I/ does not have any function synchronically. I follow Dimmendaal in representing it as a separate morpheme, without providing a gloss, however. Short vowels such as the suffix /-I/ devoice in word-final position under conditions that are laid out in detail in Dimmendaal and Breedveld [1986]. They are symbolized by V in Dimmendaal's transcriptions, but are often omitted in my own transcriptions of the language.

The epenthetic segment $/-\mathrm{k}-/$ is inserted before verbs of class 2 in the infinitive, the gerundive and the instrumental forms. 
The habitual marker/-e:n/ and the gerund suffix /-e/ in (11)-(15) exemplify the second type of suffix. They always surface as [+ATR], regardless of the quality of the preceding root. Furthermore, if a [-ATR] root is combined with one of these suffixes, a change in its tongue root quality can be observed. The (a) example of each group in (12) through (15) reveals that the root is [-ATR] underlyingly, taking [-ATR] suffixes; the other examples demonstrate that the root surfaces as [+ATR] if followed by the habitual or gerund suffix.

(11)
a. /a-kI-duk/
INF-e-build
[akiduk] 'to build'

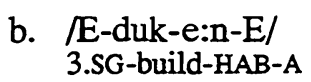
[eduke:ne] 's/he always builds'
c. /E-duk-e/ M.SG-build-GER
[eduke] 'way of building'

(12)
a. /a-k-Imuj-ar-I/ INF-e-eat-EL-?
[akımujar] 'to eat that way'
b. /a-k-Imuj-e:n-I/ INF-e-eat-HAB-?
[akimuje:ni] 'to eat regularly'
c. /E-k-ImUj-e/
[ekimuje] 'way of eating'

(13)
a. /a-dem-ar-I/
[ademar] 'to take away'
b. /E-dem-e:n-E/
[edeme:ne] 's/he always takes'
c. /E-dem-e/
M.SG-take-GER
[edeme] 'way of taking'

(14)
a. /a-dok-ar-I/ INF-climb-EL-?
[adoqar] 'to climb that way'

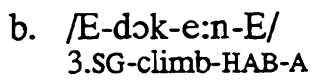
[edoke:ne] 's/he always climbs'
c. /E-dok-e/
M.SG-climb-GER
[edoke] 'way of climbing' 

(15)
a. /a-k-Ilip-ar-I/
INF-e-beg-EL-?
[akılıpar]
'to pray, beg'
b. /E-Ilip-e:n-E/
[ilipe:ne] ${ }^{5} \quad$ 's/he always prays'
c. /E-k-Ilip-e/
M.SG-e-beg-GER
[ekilipe] 'way of praying'

Examples such as these are at the basis of the claim that only one value of a distinctive feature (in this case [+ATR]) is active phonologically, in the sense of causing assimilation, while the other value is passive or phonologically inert. For almost two decades the prevailing assumption about systems such as this has been that the passive or inert value is unspecified at the deepest level of the phonology [Ringen 1975; Kiparsky 1981, 1982; Archangeli 1984; Archangeli and Pulleyblank 1986]. If both values of the feature [ATR] were part of the underlying representation, we would not be able to explain why it is the [+ATR] value of the habitual and gerund suffixes in (11)-(15) that determines the tongue root quality of the entire word, and not the [-ATR] value of the root. If, on the other hand, only [+ATR] is specified underlyingly, then this phenomenon finds a straightforward explanation: [-ATR] cannot spread, because it is literally absent from the representation.

The data considered so far are, however, incomplete in one important respect: next to the invariant [+ATR] suffixes, Turkana also has a set of suffixes which do not harmonize with a preceding [+ATR] root, but always surface as [-ATR]. Examples are the instrumental marker /-Et/ in (16)-(19) and the subjunctive suffix $/-r \varepsilon /$ in (20).
a. /a-kI-bu/
[akibu] 'to swell'
b. /a-bu-et/
[abuet] 'acromegaly (sg.)'

(17)
a. /a-kI-tub/
[akitub] 'to judge'
b. /a-tub-et/
[atubet] 'judgement (sg.)'

(18)
a. /a-kI-tin/
[akitin] 'to handle'
b. /a-tin- $\mathrm{ft} /$
F.SG-handle-INST
[atinet] 'handle (sg.)'

5 The third person singular marker /E-/ merges with the initial high front vowel of class 2 verb roots; cf. Dimmendaal [1983] for further discussion. 
(19)
a. /a-kI-mat/
[akımat]
'to drink'
INF-e-drink
b. /a-mat-et/
F.SG-drink-INST
[amazet] ${ }^{6}$ 'cup (sg.)’

(20) a. -bun

'come (sg.)'

b. /a-bun-I-A-r $\varepsilon /$

INF-come-V-V-SUBJ

[abunere] 'come (sg.)'

(21) a. -iboyikin

'sit down'

b. /E-iboyikin-I-A-re/

[iboyikinere] '(why) is it sat down?'

(22) a. $-d u k$

'build'

b. /E-duk-I-A-re/

3.SG-build-V-V-SUBJ

[edukere] '(why) is it built?'

If a harmonizing suffix like the plural marker $/-\mathrm{A} /$ is attached to one of these morphemes, it surfaces as [-ATR], as in (23).

(23)
a. /ga-bu- $\varepsilon t-A /$
[nabucta] 'acromegaly (pl.)'
F.PL-Swell-INST-PL
[natubeta] 'judgement (pl.)'
b. /ga-tub-et-A/
c. /ga-k-idik-et-A/
[nakidiketa] 'agglutination (pl.)'
d. /ga-tin-et-A/
F.PL-handle-INST-PL
[natineta] 'handle (pl.)'

6 Note that the root-final coronal stop/t/ spirantizes to /s/ before a front vowel. This is a general phonological process that applies only across morpheme boundaries, that is, in "derived" environments [Kiparsky 1982]. Spirantization is strictly limited to the phonological word, e.g., it fails to apply in compounds. That spirantization applies before the instrumental suffix /-Et/ provides crucial evidence that it forms part of the phonological word of Turkana and so cannot be considered either a clitic or an otherwise phonologically "non-cohering" affix of this language [Booij and Rubach 1984, 1987].

7 In these constructions /-re/ is always preceded by a mid front vowel which Dimmendaal [1983] analyzes as a contraction of the two voice markers /-I/ and /-A/. / -re/ also occurs in the infinitive form of ingressive verbs. If the verb is intransitive, as in (20a), it is also preceded by the two voice markers $/-\mathrm{I} /$ and $/-\mathrm{A} /$. 
The elative marker /-ar/ in (24) also belongs to this group of suffixes. Treatment of this formative is complicated by the fact that it has two variants, /-ar/ and /-or/, whose occurrence is determined by the [ATR] quality of the preceding morpheme. The first example in (24) demonstrates that the elative suffix surfaces as /-ar/after a [-ATR] root, while the remaining examples show that it is realized as /-or/ after a [+ATR] root. This is a manifestation of a more general process of low vowel raising which will be discussed in more detail in section 4 .
a. /a-k-Irtt-ar-I/
[akirtar] 'to chase away'
b. /a-dun-ar-I/
[adunor] 'to cut open'
c. /a-rip-ar-I/
INF-skim-EL-?
[aripor] 'to skim off'
d. /a-buk-ar-I/
INF-pour-EL-?
[abuqor] 'to pour out'
e. /a-k-ilik-ar-I/
INF-e-swallow-EL-?
[akiliqor] 'to take down'

An unspecified suffix is realized as [-ATR] if attached to the elative suffix.
(25)
a. /E-ilik-ar-It/
3.SG-Swallow-EL-A
b. /E-duk-ar-It/
3.SG-build-EL-A
[ilikortt] 'it is taken down'
[edukorit] 's/he builds over there'

How can we account for the invariant behavior of these suffixes? I suggest that their invariance be marked in their phonological representation, by specifying them as [-ATR] underlyingly. If [+ATR] spreading is a feature-filling process, it cannot affect these formatives. Furthermore, the line crossing constraint [Goldsmith 1976] prevents the spreading of the feature [+ATR] past the [-ATR] specification of these suffixes.

Before presenting further evidence for this position, let us posit three kinds of suffixes in Turkana (specified as [+ATR], specified as [-ATR], and unspecified for this feature) and consider what assumptions we need to make about the process of initial association and spreading. If some morphemes have a floating entry for the feature [ATR] underlyingly, this feature must associate with at least one vowel of its host morpheme before spreading to the vowels of neighboring morphemes. This assumption is easily accomodated if every morpheme is represented on a distinct phonological plane in the lexicon and if initial association takes place before plane conflation [McCarthy 1979, Cole 1987]. For reasons to be discussed in section 4, I 
assume that the initial anchor of association is the rightmost vowel in the morpheme. Furthermore, I assume that [ATR] is dependent on the tongue root articulator [Halle 1989, 1992] and that only non-consonantal segments are specified for this articulator, which excludes all consonants as targets of association.

(25) Initial association:

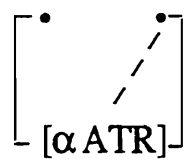

(26)

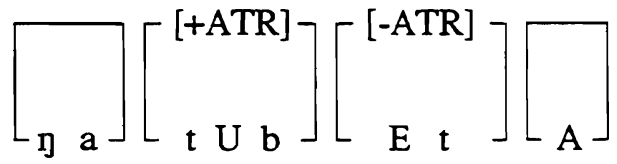

$\downarrow[\mathrm{R} 25]$

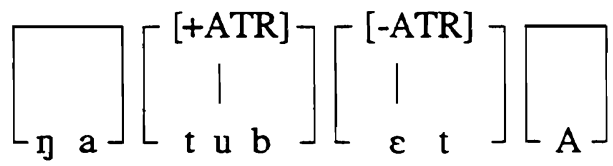

$\downarrow$ (plane conflation)

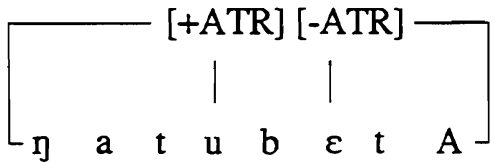

[natubeta] 'judgement (pl.)'

If initial association took place after plane conflation, the vowels of invariant suffixes would surface with an [ATR] specification other than the one they bear underlyingly, as demonstrated by the derivation in (27) below. 
(27)

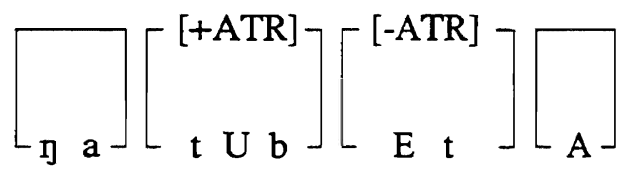

$\downarrow$ (plane conflation)

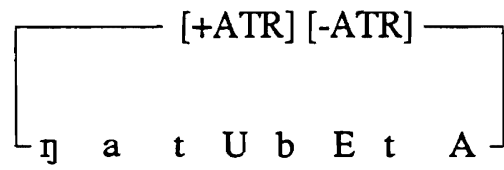

$\downarrow[\mathrm{R} 25]$

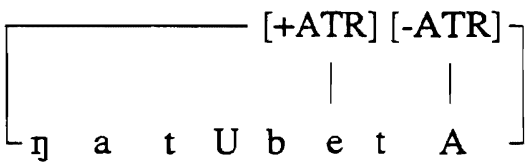

*[natubeta]

In the remainder of this paper I assume that initial association and plane conflation have already applied. (Dashes are included in the derivations for orientation purposes only.)

A consequence of the assumption that the vowels of invariant morphemes are at least partly specified when planes are conflated is that there must be two rules of [+ATR] spreading, one that associates all unspecified vowels to the left of a [+ATR] morpheme with this feature value, and another that spreads this value to all unspecified vowels on the right. 8

(28) progressive [+ATR] spread:

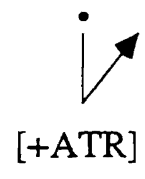

(29) regressive [-ATR] spread:

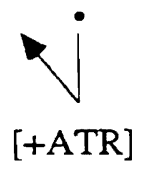

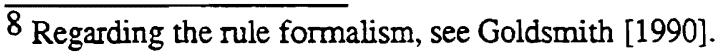


Vowels that do not receive a [+ATR] feature through spreading obtain the specification [-ATR] by the redundancy rule in (30). Whether this is a languagespecific or a universal rule is of no consequence to the discussion at this point.

(30) [-ATR] redundancy rule: [+syll] $\rightarrow$ [-ATR]

(31)

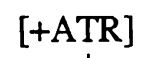

g $i-r \circ t-i n$

[nirotin] 'road (pl.)'

(32)

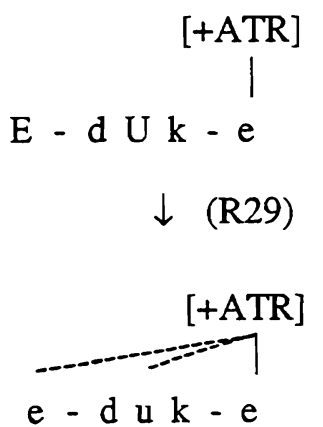

$\mathrm{e}-\mathrm{d} \mathrm{uk}-\mathrm{e}$

[eduke] 'way of hiding' 
(33)

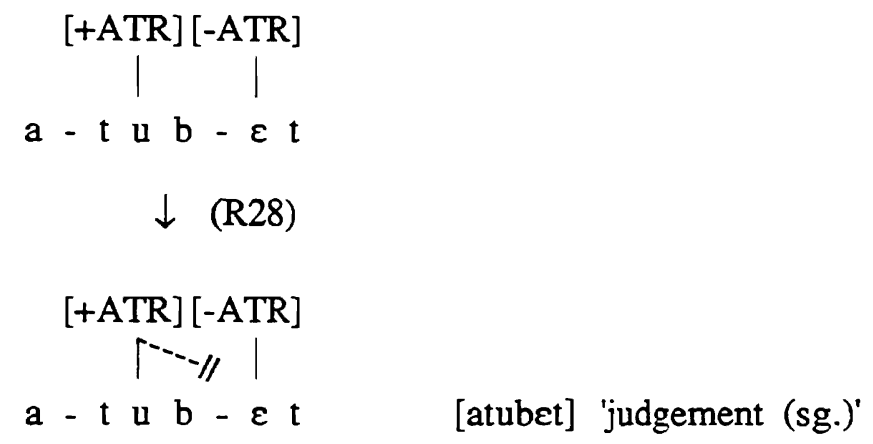

There is one consideration that lends strong support to the assumption that the invariant [-ATR] suffixes of Turkana are specified as [-ATR] underlyingly: they cause regressive assimilation. A [+ATR] mid vowel is realized as [-A TR] if followed by either the elative or the subjunctive suffix. The (a) examples in (34)(37) demonstrate that the root is [+ATR] underlyingly; the (b) examples show that the root vowel is realized as [-ATR] if followed by the elative suffix.

(34)
a. /a-kI-lep/
[akilep] 'to milk'
b. /a-lep-ar-I/
INF-milk-EL-?
[alepor] 'to milk out'

(35)
a. /a-kI-gol/
[akigol] 'to close'
INF-e-close

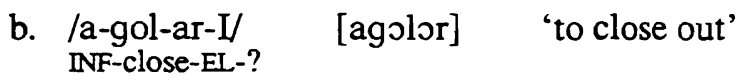

(36)
a. /a-kI-rem/
[akirem] 'to spear'
b. /a-rem-ar-I/
INF-spear-EL-?
[aremor] 'to spear over there'

(37)
a. /a-kI-bon/
[akibon] 'to retum'
b. /a-bon-ar-I/
[abonor] 'to return to a place over there'

That [-ATR] spreading is unbounded, affecting any preceding mid vowel, is illustrated by the (b) example in (38). High vowels and glides block this process, 
shown by (39b), whose mid prefix vowel surfaces as [+ATR] because it is followed by a high root vowel.

(38)
a. /E-bob/
[ebob]
'it is sweet'
3.SG-be sweet

b. /E-bob-An-ar/

3.SG-be sweet-HAB-EL

[عbobonor] 'it loses its sweetness'

(39)
a. /a-bul-ar-I/
[abulor] 'to cut open'
INF-cut-EL-?

b. /E-bul-An-ar/

[ebulonor] 's/he usually cuts open'

3.SG-cut-HAB-EL

The same phenomenon can be observed when the subjunctive marker /-re/ is attached to a mid vowel root: the preceding mid vowels surface as [-ATR].

(40)
a. /a-kI-mor/
[akimor] 'to insult'
INF-e-insult
b. /E-mor-I-A-re/
[عmorere] '(why) is he insulted?'

(41)
a. /a-kI-rem/
[akirem] 'to spear'
b. /E-rem-I-A-re/
3.SG-spear-V-V-SUBJ
[عremere] '(why) is it speared?'

(42)
a.
INF-e-pick
[akiger] 'to pick, pluck'
b. /E-ger-I-A-re/
3.SG-pick-V-V-SUBJ
[عgerere] '(why) is it picked?'

As expected, any [+high] vowel or glide interferes with this process, as illustrated by the examples in (43)-(45).
a. /a-kI-dol/
[akidol]
'to arrive'
INF-e-arrive

b. /E-ItV-dol-Un-I-A-re/

[itodolunere] '(why) is s/he made to arrive?'

\section{SG-CAUS-arrive-AL-V-V-SUBJ}



a. /a-kI-gol/
[akigol]
'to close'

b. /E-gol-akIn-I-A-re/ 3.SG-close-DAT-V-V-SUBJ

[egolokinere] '(why) is it closed?'

(45)
a. /a-k-igor/
[akigor]
'to cry'
b. /E-ItV-igor-I-A-re/
3.SG-CAUS-cry-V-V-SUBJ
[izigorere] '(why) is s/he made to cry?'

The elative and subjunctive suffixes are thus unusual in yet another respect: apart from not undergoing [+ATR] harmony, they can cause a shift in the quality of a preceding mid vowel from [+ATR] to [-ATR]. This observation finds a straightforward explanation if we assume that these suffixes are specified as [-ATR] underlyingly and spread their [-ATR] value to the left, since this establishes a direct connection between the quality of these suffixes and the effect they have on the preceding vowels. By contrast, if we were to assume that non-alternating [-ATR] suffixes are unspecified for [ATR] underlyingly and simply marked by an exception feature for not undergoing [+ATR] harmony, we would claim that there is no correlation between these two phenomena.

[-ATR] spreading is feature-changing and parasitic in nature, i.e., trigger and target must share some contextual feature for spreading to apply [Cole 1987, Cole and Trigo 1988]. I assume that this contextual feature is [-high]. A high vowel or glide that occurs between a [-ATR] suffix and a preceding mid vowel blocks regressive [-ATR] spreading by virtue of being specified as [+high].

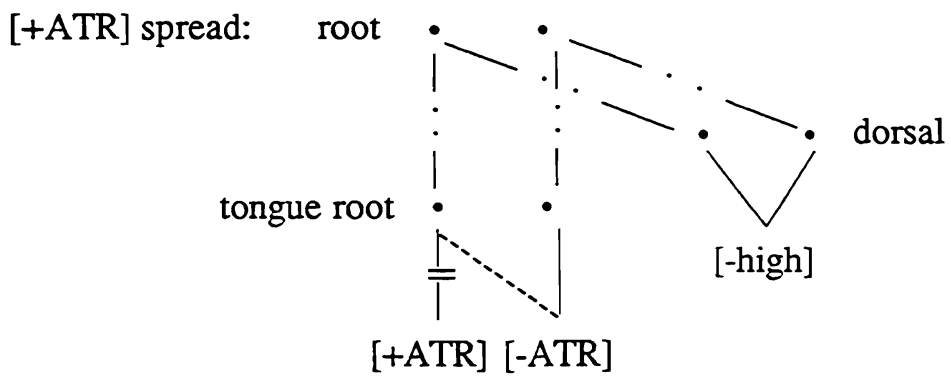

[-ATR] spreading is illustrated in (47) by the elative suffix/-ar/. The low suffix vowel is raised and underlying adjacent [-high] features are merged by the OCP before [-ATR] spreading applies. 
(47)

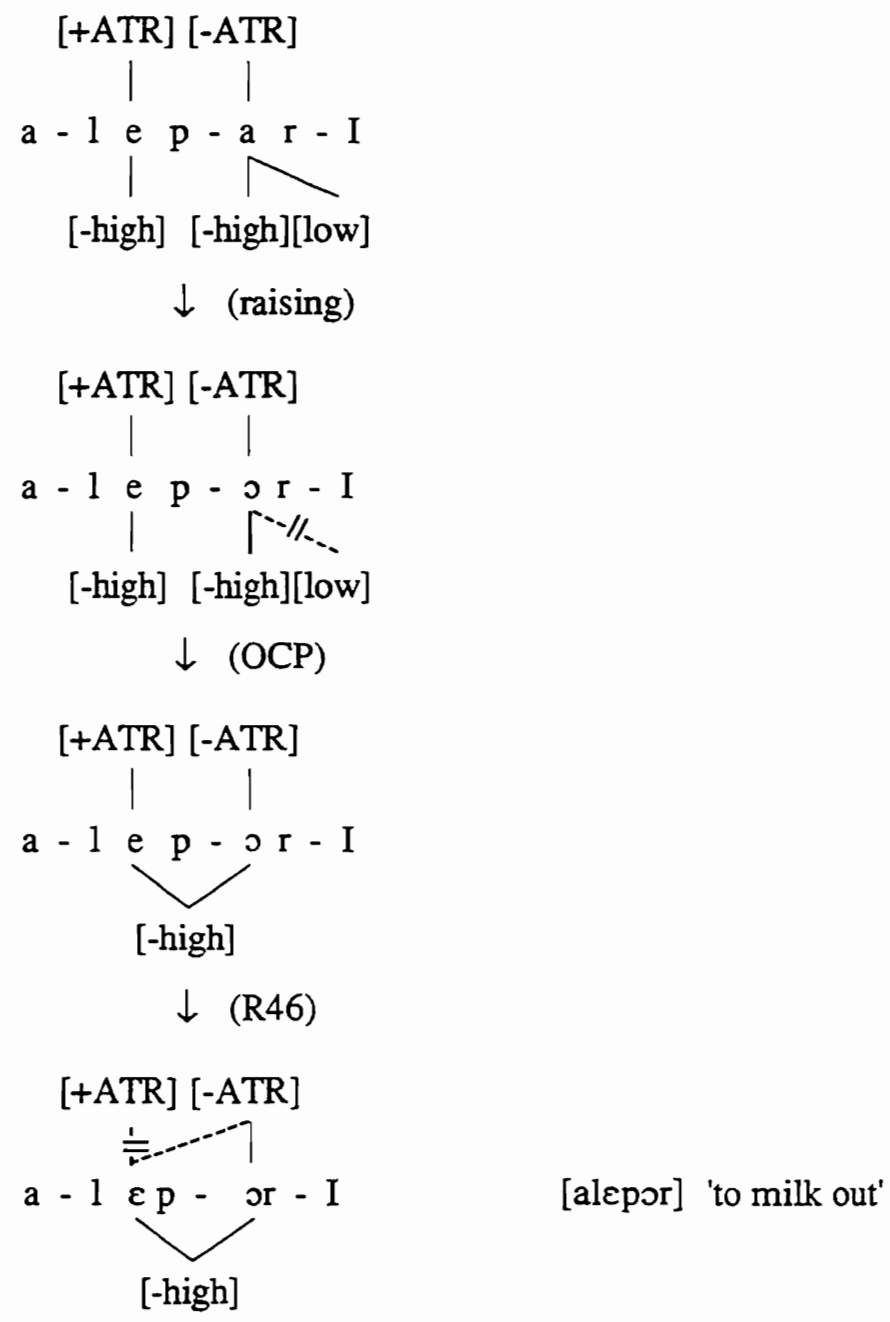

To summarize, there are two phenomena that lead to the conclusion that the non-altemating [-ATR] suffixes of Turkana are specified as [-ATR] underlyingly: (i) they fail to undergo [+ATR] harmony, and (ii) they cause a shift in the quality of any number of preceding, contiguous mid vowels from [+ATR] to [-ATR]. Each of these phenomena independently provides justification for the assumption that the non-alternating [-ATR] suffixes are lexically specified as [-ATR]. When taken together this evidence is overwhelming. Therefore, I conclude that there are three kinds of suffixes in Turkana: (i) those that are unspecified for [ATR] and alternate, (ii) those that are specified as [+ATR] and cause unlimited regressive assimilation, 
and (iii) those that are specified as [-ATR] and cause regressive assimilation of mid vowels.

Throughout this section I have assumed that roots are either specified as [+ATR] or unspecified for this feature underlyingly and that regressive [+ATR] Spread is feature-filling only. Unspecified roots that are not combined with a dominant [+ATR] suffix receive a [-ATR] specification by the redundancy rule in (30). Given that suffixes can be specified as [-ATR] underlyingly and spread this feature in a structure-changing fashion, it could be argued that roots are also specified as [-ATR] underlyingly. It would follow that not only regressive [-ATR] spread, but also regressive [+ATR] spread is feature-changing. Progressive [+ATR] spread (28), by contrast, would be feature-filling and leave the underlying [-ATR] specification of suffixes intact.

While this alternate solution is as feasible as the approach pursued here, it does not change the most important conclusion that must be drawn from the Turkana system, namely that languages make use of ternary contrasts in features underlyingly. The force of the argument for an underlying temary contrast comes from the behavior of suffixes, which clearly fall into three classes: (i) specified as [+ATR], (ii) specified as [-ATR], and (iii) unspecified for [ATR]. The only consequence of assuming that roots are specified as [-ATR] underlyingly is that underspecification is limited to suffixes as a morphological category, but this does not invalidate the ternary hypothesis.

\section{Low Vowels}

There are further restrictions on the occurrence of the feature [ATR] which will be considered in this and the following sections. Let us begin with the distribution of the features [ATR] and [low]. A vowel that precedes a low vowel is always [-ATR]. However, low vowels may be followed by either a [+ATR] or a [-ATR] vowel. This is true for the distribution of the features [ATR] and [low] in morphemes and in morphologically complex words. ${ }^{9} \mathrm{~A}$ low vowel may also be preceded by a glide.
(48) a. /a/ ..... [-ATR $]$
b. $\quad / a / \ldots . . .[+A T R]$
c. $/ \mathrm{y}, \mathrm{w} / \ldots \ldots . . . . \mathrm{a} / \mathrm{a}$
d. $[$-ATR $] \ldots . . . . / \mathrm{a} /$
e. * $[$ HATR $] \ldots . . . . / \mathrm{a} /$

9 Dimmendaal [1983] mentions one exception to this claim, namely the root -turkana 'Turkana' in which the low root vowel is preceded by a [+ATR] vowel. He also points out that this root is frequently realized with a glide between the [+ATR] vowel and the low vowel, as in [niturkwana] 'the Turkana people', in which case it does not violate the structure condition in (54e). 
Two phonological processes of Turkana conspire to this end: (i) low vowels in suffixes raise to mid after a [+ATR] morpheme; (ii) low vowels spread the value [-ATR] to the left.

A suffixal low vowel is raised to mid after a [+ATR] root; that is, /a/ occurs after a [-ATR] root, while $/ \mathrm{o} /$ is found after a [+ATR] root. Examples of this process are given in (49)-(51). Raising from $/ \mathrm{a} /$ to $/ \mathrm{o} /$ provides important systematic evidence for the [ATR]-quality of morphemes, since only [-ATR] morphemes are followed by low vowel suffixes, while [+ATR] morphemes are always followed by mid vowel suffixes.

(49)
a. /a-muk-At/
F.SG-shoe-SG
[amuqat] 'shoe (sg.)'
b. /E-pur-At/
[epurot] 'beer (sg.)'
c. /E-tIm-At/
[Etrmat] 'hair of head (sg.)'
d. /E-pipi-At/
M.SG-firestick-SG
[epipyot] 'firestick (sg.)'
e. /E-kor-At/
M.SG-Samburu-SG
[eqorot] 'Samburu person (sg.)'

(50) a. /a-duk-AkIn-I/ [adukakun] 'to hide for s.o.' INF-hide-DAT-?
b. /a-duk-AkIn-I/ INF-build-DAT-?
[adukokin] 'to build for s.o.'

c. /a-k-ilip-AkIn-I/ [akılipakın] 'to pray, beg for s.o.' INF-e-pray-DAT-?
d. /a-pet-AkIn-I/ INF-kick-DAT-?
a. /E-ka-ñer-A-nI/

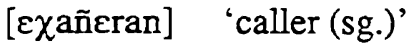
b. /nI-ka-bon-A-k/
[gikabojoq] 's.o. who returns (pl.)'
c. /E-ka-mo-n-A-nI/ M.SG-AG-be mean-SG-V-SG

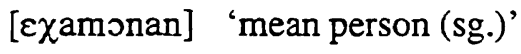
d. /pI-ka-dol-A-k/
M.PL-AG-arive-V-PL
[ Iikadoloq] 's.o. who arrives (pl.)' 
The example in (52b) illustrates that low vowel raising affects any number of low vowel suffixes.

(52)
a. /E-ka-lat J-AkIn-A-nI/ M.SG-AG-let-DAT-V-SG

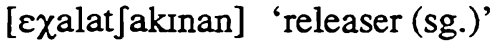
b. /E-ka-lep-AkIn-A-nI/ M.SG-AG-milk-DAT-V-SG

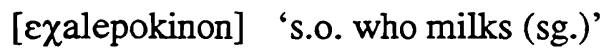

By contrast, a low prefix vowel does not raise if followed by a [+ATR] root (53).

(53)
a. /a-koro/ [aqoro] 'hunger'
F.SG-hunger
b. /a-gol-Un-I/ [agolun] 'to close in'
INF-close-AL-?

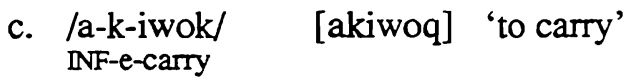

Also, a low root vowel does not raise if it is followed by a [+ATR] suffix, like the gerund marker /-e/ or the habitual suffix /-e:n/.

(54)
a. /E-ram-e/
[عrame] 'way of beating'
b. /E-cal-e/
M.SG-scream-GER
[عt]ale] 'noise, way of screaming'

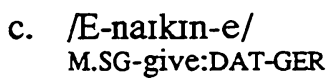
[enaikine] 'way of giving'
d.
3.sG-beat-HAB-A
[Erame:ne] 's/he usually beats'

Finally, raising fails to apply to low vowel suffixes that are followed by a [+ATR] suffix, as shown in (55).

(55)
a. /E-duk-AkIn-e/
M.SG-hide-DAT-GER
[عdvkakine] 'way of hiding for s.o.'

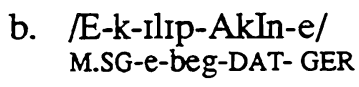
[عkllpakine] 'way of praying for s.o.'
c. /E-k-Inok-AkIn-e/
[ekmoqakine] 'way of lighting for s.o.' 

(55)
d. /E-k-rlot-ar-e/ M.SG-e-wash-EL-GER
[عklotare] 'way of washing'

The generalization that emerges from these data is that a low vowel raises if it is preceded, but not if it is followed, by a [+ATR] morpheme. Let us first examine what the nature of the raising process is. At first sight it might appear as if raising resulted from the association of a low suffix vowel with the feature value [+ATR]; a low vowel that receives the value [+ATR] through progressive spreading automatically raises to /o/. However, there is evidence that this assumption is incorrect and that raising and [+ATR] spreading are independent processes. Consider the alternation pattern of the elative suffix /-ar/ in (56). The underlying low vowel of this suffix surfaces as /a/ after a [-ATR] root, but as the [-ATR] vowel $/ \mathrm{s} /$ after a [+ATR] root. 10 That is, even though the low suffix vowel is raised after a [+ATR] root, it does not assimilate in the feature [+ATR], which shows that raising is not an automatic consequence of [+ATR] spreading.
a. /a-duk-ar-I/
[aduqar] 'to hide that way'
INF-hide-EL-?
b. /a-dun-ar-I/
[adujor] 'to cut open'
c. /a-np-ar-I/ INF-investigate-EL-?
[arpar] 'to investigate'
d. /a-rip-ar-I/
[aripor] 'to skim off'

Presuming that we want to account for the behavior of all low vowel suffixes by a single rule, we need to assume that first a low suffix vowel is raised by the rule in (57), and that [+ATR] spreading applies to the suffixes in (49)-(51) only after raising. Raising consists of the delinking of an underlying [low] feature.

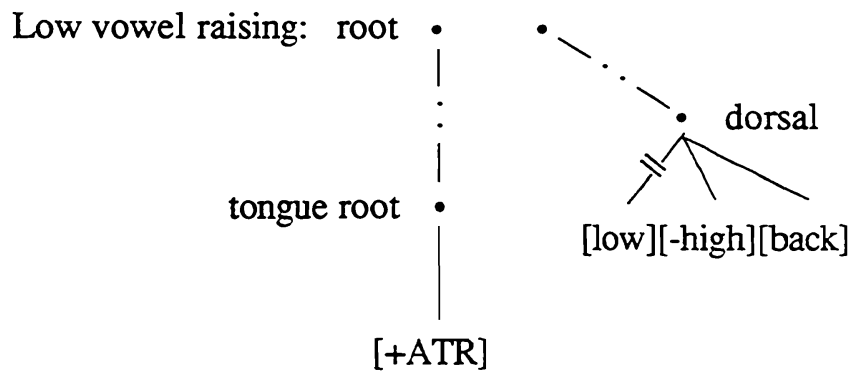

$\overline{10}$ While the elative is the only suffix in Turkana that shows this behavior, the a $\sim 0$ alternation pattern is more widespread in the closely related language Ateso [Rottland and Otaala 1983]. 
The derivation in (58) demonstrates the operation of this rule.

(58)

$$
\begin{aligned}
& \text { [+ATR] } \\
& \mid \\
& \mathrm{E}-\mathrm{k} \text { or }-\mathrm{A} \mathrm{t} \\
& \downarrow \text { (R57) } \\
& \text { [+ATR] }
\end{aligned}
$$

Next, let us turn to the behavior of low vowels in positions other than suffixes. As already mentioned, a non-initial low vowel is always preceded by [-ATR] vowels, but may be followed by vowels of either harmony category. Polysyllabic roots with a medial or final low vowel are comparatively rare; (59) presents a few such cases. In these examples, the low vowel is preceded and followed by [-ATR] vowels in the same morpheme.

(59) a. /E-sikarajur/ [Ezıqarajor] 'molasses' M.SG-molasses
b. /a-kuja/
[akuja]
'pool, well (sg.)'
c. /E-cupa/
M.SG-bottle
[et Jupa] 'bottle (sg.)' 
Even rarer are examples in which a low vowel is preceded by a [-ATR] and followed by a [+ATR] vowel tauto-morphemically. (60) displays the only two examples I was able to find.

(60)
a. /a-rmatoi/
F.SG-respect
[arimatoy] 'respect'
b. /E-k-Inareni/ M.SG-e-?
[ekınareni] 'already'

The following examples contain a low vowel in root-initial position which is followed by either a tauto-morphemic [-ATR] or [+ATR] vowel. The examples in (61a-c) demonstrate that roots with an initial low vowel take [-ATR] prefixes, even if the second root vowel is [+ATR]. [+ATR] can apparently not spread past the low root vowel to a non-low prefix vowel.
(61)
a. /E-kale:s/
M.SG-ostrich
[عqale:s] 'ostrich (sg.)'
b. /E-ma:nik/
[عma:nik] 'bull (sg.)'
c. /E-natuñ/
M.SG-lion
[عฤatuñ] 'lion (sg.)'
d. /E-ma:se/
[ema:ze] 'locust (sg.)'
e. /E-nalur-A/
[عnalura] 'kidney (sg.)'

That low vowels impede the regressive propagation of [+ATR] and so are opaque is also confirmed by the following examples in which a dominant [+ATR] suffix is attached to a low vowel root. The reader will observe that the non-low prefix vowel surfaces as [-ATR] in this context, instead of assimilating in [+ATR] to the suffix.
a. /E-ram-e/
M.SG-beat-GER
[عrame] 'way of beating'
b. /E-cal-e/
M.SG-scream-GER
[Et]ale] 'noise, way of screaming'

Low vowels are unspecified for [ATR] underlyingly. Evidence for this assumption has already been presented in the preceding discussion of low vowel raising. The low suffix vowels in examples (49)-(51) associate with the feature value 
[+ATR] after raising. Since [+ATR] Spread is feature-filling only, these vowels must be unspecified for [ATR] underlyingly. Unlike non-low vowels, low vowels cannot associate with the feature value [+ATR], because of the universal markedness constraint $*[+\mathrm{ATR},+\mathrm{low}]$ which rules out the co-occurrence of these two feature values [Archangeli and Pulleyblank 1994]. They receive a [-ATR] specification by the rule in (63).

(63) [-ATR] redundancy rule (low vowels): [+syll, low $] \rightarrow$ [-ATR]

The question is at what point in the derivation this redundancy rule applies. I argue that it applies before regressive [+ATR] spreading, so that low vowels block the spreading of [+ATR] by virtue of the constraint against crossing association lines [Goldsmith 1976]. Since the ordering of these rules does not follow from any independent principle of phonological theory, it is extrinsic.

Consider the following facts about low vowel roots: it was already established that low vowel roots are always preceded by [-ATR] prefixes. In general, they also cause [-ATR] harmony in suffixes, as shown in (64).
a. /a-rap-Un-I/
INF-discover-AL-?
[arapun] 'to discover'
b. /a-tam-Un-I/
[atamun] 'to remember'
c. /a-cam-Un-I/
INF-like-AL-?
[at [amun] 'to like, agree'

There are, however, a number of nouns that take [+ATR] plural suffixes, even though they contain a single low vowel at the surface. These include several loanwords from English and Swahili (65)-(67), but also words of the native Turkana lexicon (68).
a. /a-gar/
[agar]
'car (sg.)'
b. /ga-gar-IA/
[nagaryo] 'car (pl.)'

(66)
a. /a-kabat/
[axabat]
'cupboard (sg.)'
b. /ga-kabat-IA/
[naxabatyo] 'cupboard (pl.)' 
(67)
a. /a-kad/
[axad]
'card (sg.)'
b. /na-kad-IA/
[ gaxadyo] 'card (pl.)'
F.PL-card-PL

(68)
a. /E-lap/
M.SG-moon
[Elap]
'moon, month (sg.)'
b. /nI-lap-IA/
[mllapyo] 'moon, month (pl.)'

The examples in (65)-(68) contrast with the loan-words in (69)-(70) below which take [-ATR] suffixes.
(69)
a. /a-bas/
F.SG-boss
[abas]
'boss (sg.)'
b. /ga-bas-IA/
[nabazia]
'boss (pl.)'
F.PL-boss-PL
(70)
a. /E-ka:s/
M.SG-work
[عqa:s]
'work (sg.)'

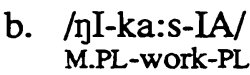
[nıqa:zıa] 'work (pl.)'

To account for the occurrence of [+ATR] suffixes in the plurals of (65)-(68), we need to assume that the lexical representation of these noun roots includes a floating [+ATR] feature. This [+ATR] feature cannot associate with the low root vowel, but when a high vowel is supplied via suffixation, linking becomes possible. Note that the plural form in (68) provides justification for the claim that the direction of initial association is to the right. If initial association were to the left, the prefix vowel should surface as [+ATR], while the suffix vowels should be realized as [-ATR].

The important forms to consider in the context of the present discussion are, however, the singular prefixes and not the plural suffixes. The reader should notice that the non-low prefix vowel in the singular form in (68) surfaces as [-ATR]. This is surprising, considering that it is the rightmost eligible vowel and so a legitimate target for association with the floating [+ATR] feature of the root after prefixation. If the analysis presented so far was correct, we would expect this vowel to surface as [+ATR]. 
(71)

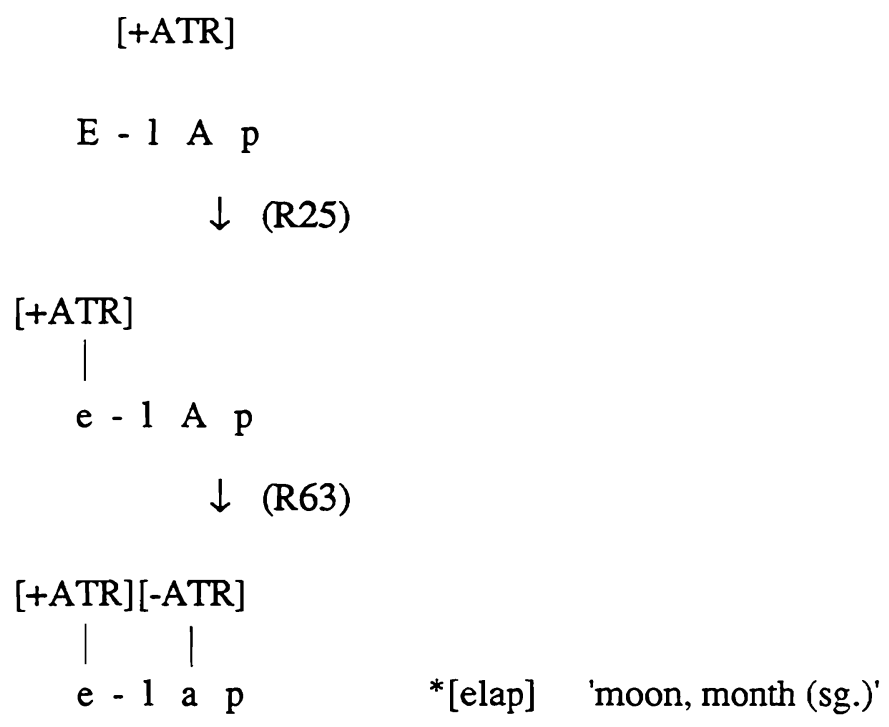

The only way that we can account for the occurrence of a [-ATR] prefix vowel in this form is to assume that [-ATR] spreads from the low vowel to the non-low prefix vowel by the rule in (72).

(72) [-ATR] spread from low vowels: root

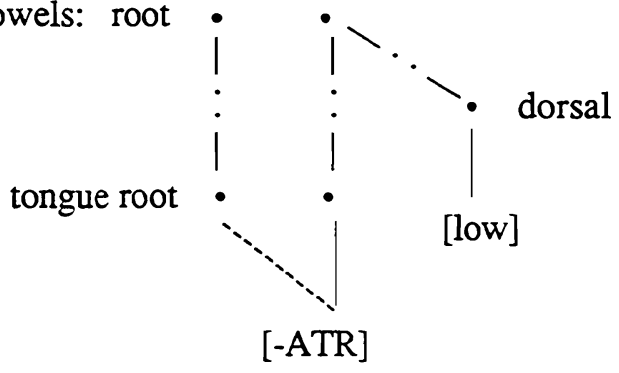


(73)

$$
\begin{aligned}
& \text { [+ATR] } \\
& \text { E - } 1 \text { A p } \\
& \downarrow \text { (R63) } \\
& \text { [-ATR] [+ATR] } \\
& \mid \\
& \text { E - } 1 \text { a p } \\
& \downarrow \text { (R72) }
\end{aligned}
$$

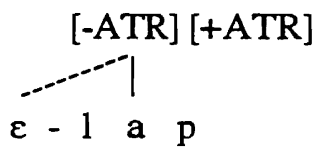

[Elap] 'moon, month (sg.)'

There is another conclusion that can be drawn from this discussion: since low vowels receive a [-ATR] specification by rule and spread this value leftward, we can assume that they block the regressive propagation of [+ATR] on the basis of the line crossing constraint, as illustrated by the derivation below.

(74)

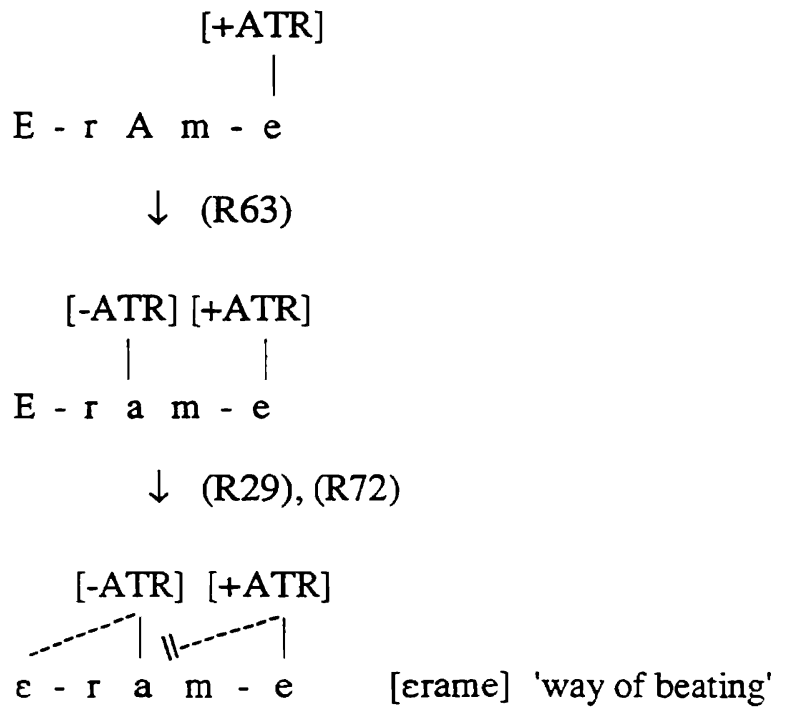


The redundancy rule in (63) must therefore apply before regressive [+ATR] spreading (29). Raising (57), on the other hand, must apply before the redundancy rule in (63), since a low suffix vowel can associate with the feature value [+ATR] after raising.

(75) Summary of proposed rule ordering

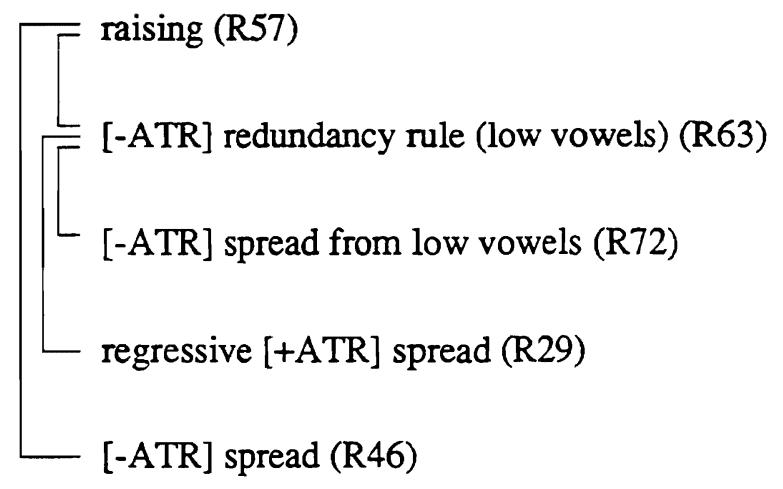

\section{Glides}

There is another restriction on the occurrence of the feature [ATR] in Turkana: a vowel preceding a glide is always [+ATR]. However, a glide can be followed by a tauto-morphemic vowel of either harmony category. In addition, glides may be preceded by low vowels.

(76) a. $/ y, w / \ldots . . .[+$ ATR $]$

b. $\quad / y, w / \ldots . . .[-A T R]$

c. $/ \mathrm{a} / \ldots \ldots \ldots . . . . . . / \mathrm{y}, \mathrm{w} /$

d. $\quad[+\mathrm{ATR}] \ldots . . . / \mathrm{y}, \mathrm{w} /$

e. * $[$-ATR $] \ldots . . . . . / \mathrm{y}, \mathrm{w} /$

The set of examples in (77) presents several polysyllabic roots in which a glide is preceded by a [+ATR] vowel in the same morpheme. In the first two examples, the glide is straddled by a [+ATR] and a [-ATR] vowel. In the remaining examples, all vowels surrounding the glide are [+ATR]. 
(77)
a. /E-kedyeñ/
M.SG-be left-handed
b. /a-k-imyel/

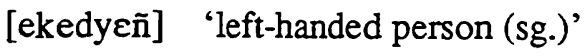
c. /a-k-irwor/
[akimyel] 'to taste'
d. /a-k-iwok/
[akirwor] 'to speak'
INF-e-carry
[akiwoq] 'to carry'
e. /E-ruye/
M.SG-blare
[eruye] 'blare (sg.)'

The examples in (78) illustrate that glide-initial roots take [+ATR] prefixes, even if the glide is followed by a [-ATR] vowel. These forms show that glides actually bear a [+ATR] specification and spread this feature to the left. If glides were neutral, the prefix vowel would be expected to surface as [-ATR] in agreement with the root vowel.

(78)
a. /a-kI-yep/ [akiyep] 'to cut'
INF-e-cut
b. /a-kI-gyel/ [akigyel] 'to buy'
INF-e-buy

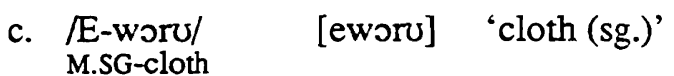
d. E-yen-I/ [eyenI] 's/he knows'
3.sG-know-A

Glides do not contrast in the feature [ATR]. Assuming that predictable or redundant features are absent underlyingly and assigned by rule, glides have no [ATR] specification in the input to the phonology and receive a [+ATR] specification by the redundancy rule in (79).

(79) [+ATR] redundancy rule (glides): [-syllabic, -consonantal] $\rightarrow$ [+ATR]

The question is again at what point in the derivation the redundancy rule in (79) applies. Glides spread their [+ATR] value to the left. If we want to account for regressive [+ATR] spreading from roots and suffixes and spreading from glides by a single rule, progressive [+ATR] spread must take place before glides are assigned their [+ATR] value, so that they cannot participate in this form of spreading. progressive [+ATR] spread must, therefore, be ordered to apply before the redundancy rule in (79) and regressive [+ATR] spread. 
(80) Summary of proposed rule ordering

[ progressive [+ATR] spread (R28)

[ [+ATR] redundancy rule (glides) (R79)

regressive [+ATR] spread (R29)

The derivation in (81) illustrates this order.

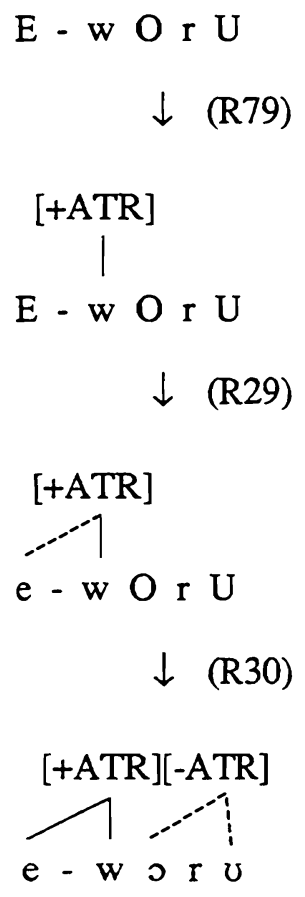

e - w 0 r U

[eworu] 'cloth (sg.)'

Despite the fact that glides can be followed by either a [+ATR] or a [-ATR] vowel, Dimmendaal [1983] remarks that mid vowels often sound "tense" if preceded by a glide, transcribing them as [o] and [e]. He describes these vowels as having a "harsh" or "tense" voice quality which is usually associated only with the feature [-ATR], but, nevertheless, being produced with an advanced tongue root. Based on this description, Trigo [1991] proposes that the "tense" vowels [o] and [e] in Turkana are of a mixed harmony register: they are produced with an advanced tongue root and a raised larynx, which causes their harsh quality. She 
argues that the existence of these vowels justifies the assumption of two phonological features [Advanced/Retracted Tongue Root] and [Raised/Lowered Larynx].

I have frequently observed that glides have an influence on the quality of a following mid vowel: an underlying [-ATR] mid vowel is often realized as [+ATR] if preceded by a glide in the onset. However, this effect is sporadic. The roots in (82)-(83), for example, consist of a glide which is followed by a [-ATR] mid vowel underlyingly, as evidenced by the fact that these roots take [-ATR] suffixes. In some constructions, the underlying [-ATR] vowel is nevertheless realized as [+ATR] without this change being due to a following dominant [+ATR] suffix.
a. /a-yen-A/
1.SG-know-V
[ayena] 'I am aware of it'
b. /a-kI-yen/
INF-e-know
[akiyen] 'to know'

(83)
a. /a-gyel-ar-I/
INF-buy-EL-?
[agyelar] 'to sell'
b. /E-gyel-It/
M.SG-buy-INSTR
[egyelit] 'price (sg.)'

These examples show that glides do, indeed, have an influence on the quality of a following mid vowel. I did not, however, notice the "harsh" voice quality that Dimmendaal associates with these vowels in this position. I therefore consider them simply [+ATR] and not of a mixed harmony register, as suggested by Trigo [1991].

The effect of glides on a following mid vowel can also be observed if a nonalternating [-ATR] suffix is attached to a mid vowel root. As already mentioned, regressive [-ATR] spreading is blocked by a high vowel or glide. Glides do not only block the regressive propagation of [-ATR], but, in addition, spread their [+ATR] value to an adjacent mid vowel on the right, which therefore surfaces as [+ATR] instead of [-ATR] as expected in this context. This phenomenon is demonstrated by the examples in (84)-(85), which should be compared to the earlier ones in (34)(37) and (40)-(42). Glides thus "protect" a following mid vowel from undergoing [-ATR] harmony. Unlike progressive [+ATR] Spread, which is unbounded, this process is clearly local, since no more than the immediately following mid vowel is realized as $[+\mathrm{ATR}]$ in this context.
a. /a-wok-ar-I/
[awoqor] 'to draw water'
INF-draw water-EL-?
b. /a-k-iryon-ar-I/ INF-e-blacken-EL-?



a. /E-isyon-I-A-re/
3.SG-remit-V-V-SUBJ
[isyonere] '(why) is it remitted?'
b. /E-ItV-igyen-I-A-re/ 3.SG-CAUS-depend-V-V-SUBJ
[izigyenere] '(why) is s/he made to depend?'

If the glide is deleted (which is an optional process), the mid vowel undergoes regressive $[-A T R]$ harmony:

(86) /a-wo-n-I-A-re/
INF-be dry-SG-V-V-SUBJ

[awonere] [aonere] 'to dry'

I assume that there is an optional rule of rightward [+ATR] Spread from glides to a following mid vowel which will not be formalized here.

Finally, there are a number of glide formation and glide deletion rules which interact in complex ways with the vowel harmony system of Turkana. An onset glide is optionally deleted if followed by a [-ATR] vowel, with concomitant lengthening of that vowel. If the glide is absent, the preceding vowel surfaces as [-ATR] instead of [+ATR]; this is shown by the examples in (87a-b).
a. /a-kI-yep/
[a.ki.yep] [a.kI.e:p] 'to cut'
b. /E-worv/
[e.wo.rv] [e.o:.rv] 'cloth (sg.)'
c. /a-yepe/
F.SG-axe

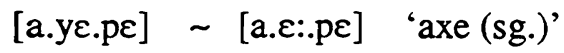

To account for this phenomenon we need to assume that glide deletion applies before the redundancy rule in (30) which assigns the value [-ATR] to any unspecified vowel.

Glide formation rules, on the other hand, are sensitive to the [ATR]-quality of high vowels and so seem to apply after [+ATR] spreading and the general [-ATR] redundancy rule. A [+ATR] high vowel is realized as a glide if followed by a back vowel, while a [-ATR] high vowel tends to remain syllabic in this context. This tendency is best observed when the plural marker /-A/ is attached to a noun root that ends in a high front vowel underlyingly (88)-(91).
(88)
a. /E-korl/ M.SG-ratel
[ع.qวr]
'ratel (sg.)'
b. /II-kori-A/
M.PL-ratel-PL
[jı.qo.n.a] 'ratel (pl.)' 
(89)
a. /E-kori/
M.SG-giraffe
[e.qo.ri] 'giraffe (sg.)'
b. /nI-kori-A/
[ni.qo.ryo] 'giraffe (pl.)'

(90) a. /a-pedi/

[a.ped] 'pile (sg.)'

b. /ga-pedi-A/

[na.pe.dr.a] 'pile (pl.)'

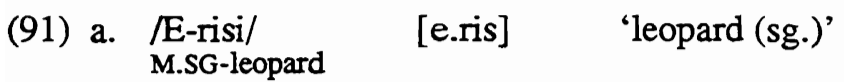

b. InI-risi-A/
M.PL-leopard-PL [i.ri.zyo] 'leopard, (pl.)'

However, exceptions to this generalization do occur. Dimmendaal [1983] presents the examples in (92)-(94) in which a [-ATR] high vowel desyllabifies into a glide and in which the preceding vowels are realized as [+ATR] as a consequence of glide formation. I have occasionally observed that a [-ATR] high vowel loses its syllabicity, as, for example, in the plural form of the words for 'night' and 'arrow' in (94b) and (95b). However, I am not able to say with certainty whether or not this results in a change in the [ATR]-quality of the preceding vowels.

(92) /a-ko:kI-A:n-ut/ F.SG-?-HAB-NOM

[a.yo:.kya:.nvt] 'loneliness; orphanhood'

(93)
/nI-rual
M.PL-day
[ni.rwa:]
'day (pl.)’

(94) a. /a-kuan/

F.SG-night

[a.ku.ar] [a.kwa:r]

'night (sg.)'

b. /ga-kuari-sIA/ [ga.kwa.ri.zya] [na.kwa.r.zya] 'night (pl.)' F.PL-night-PL

(95)
a. /E-mali/
[e.mal]
'arrow (sg.)'
b. /nI-mali-A/
[II.ma.lya]
'arrow (pl.)' 
That glide formation rules are sensitive to the [ATR]-quality of a high vowel can also be observed when a high vowel syllabifies into the coda. [+ATR] high vowels in word-final position form the coda of a preceding open syllable and so become glides. [-ATR] vowels, by contrast retain their syllabicity in this position. This generalization is also not without exceptions.

(96)
a. /ga-gulu-I/
[na.gu.luy] 'kind of pot (pl.)'
b. /jI-worv-I/
M.PL-cloth-PL
[ni.wo.rvI] 'cloth (pl.)'
c. /ga-gete-I/
F.PL-antelope-PL
[na.ge.tey] 'antelope (pl.)'
d. /E-tau/
M.SG-heart
$[\varepsilon . \operatorname{ta} U]$
'heart (sg.)'

Since [+ATR] and [-ATR] high vowels are treated differently by the glide formation rules of Turkana, it appears that glide formation applies after [+ATR] spreading and the [-ATR] redundancy rule in (30). The exceptional forms in (92)(95), on the other hand, suggest either that regressive [+ATR] spreading applies after glide formation or that it reapplies after glide formation. Further research is needed to determine the correct order of rule application.

\section{Conclusion}

The data presented in this paper provide strong evidence against the assumption that only one value of every distinctive feature is specified underlyingly while the complementary value is absent and filled in by a redundancy rule. This evidence is two-fold: first, the pattern of suffixal behavior in Turkana indicates that both values of the feature [ATR] are available at the lexical level of representation. In addition, there is evidence that some suffixes are unspecified for [ATR] underlyingly, raising the number of underlying feature values to three. Second, it can be demonstrated that the redundancy rules which assign glides and low vowels their [ATR] specification and the rules of [+ATR] spreading must be extrinsically ordered. This reliance on extrinsic rule ordering constitutes a weakening of the theory of radical underspecification which holds that all ordering relations between redundancy and spreading rules follow from independent principles of phonological theory. If redundancy rules are stipulated to apply before spreading, then the claim that redundant feature values are absent underlyingly cannot be falsified.

In evaluating the present proposal it should be recalled what the role or function of features is in phonological theory. Generative phonology holds that there is a level of representation at which the non-suppletive allomorphs of every morpheme 
have a unique phonological representation. This underlying level of representation forms the deepest level of the phonology to which the phonological rules of a language apply. Morphemes that are identical in some of their surface forms, but different in others, are usually assumed to differ in their underlying featural representation. In brief, generative phonology uses distinctive features to encode differences in morphophonological behavior. If all features are binary (and this assumption holds whether or not we espouse radical underspecification theory), then only two patterns of morpheme behavior can be distinguished.

The data presented in this paper are unusual in that we can clearly distinguish between three, and not just two, patterns of suffixal behavior, a phenomenon that cannot be accounted for as long as we assume that all features are binary. It could be argued that, instead of encoding the different morphophonological behavior of these suffixes in their underlying phonological representation, we should employ other devices, such as level ordering or rule exception features, to account for their behavior. However, the most intriguing aspect of the Turkana system is that suffixation of an invariant [-ATR] morpheme interacts with other phonological processes of the language. For example, a [+ATR] mid vowel surfaces as [-ATR] if followed by a non-alternating [-ATR] suffix. This process is unbounded, affecting the mid vowels of any number of preceding morphemes, as long as they are not interrupted by high vowels. It is entirely regular and interacts with the optional process of glide deletion and vowel contraction. Hence, the phonological changes caused by adding a non-alternating [-ATR] suffix must be accounted for in phonological terms. Indeed, it is the phonological consequences of suffixing a [-ATR] morpheme that most strongly speak in favor of the analysis presented here-an analysis that leads to the conclusion that the position that all features are binary underlyingly must be abandoned.

\section{REFERENCES}

Archangeli, Diana. 1984. "Underspecification in Yawelmani phonology and morphology." Ph.D. dissertation, MIT. [Published by Garland Press, New York, 1988.]

Archangeli, Diana. 1988. "Aspects of underspecification theory." Phonology 5: 183-207.

Archangeli, Diana and Douglas Pulleyblank. 1986. "The content and structure of phonological representations." University of Arizona and University of Southern California, ms. 
Archangeli, Diana and Douglas Pulleyblank. 1994. Grounded phonology. Cambridge, MA: MTT Press.

Booij, Geert and Jerzy Rubach. 1984. "Morphological and prosodic domains in lexical phonology." Phonology Yearbook 1:1-27.

Booij, Geert and Jerzy Rubach. 1987. "Postcyclic versus postlexical rules in lexical phonology." Linguistic Inquiry 18: 1-44.

Clements, George N. 1988. "Towards a substantive theory of feature specifications." Proceedings of the Northeastern Linguistics Society 18: 79-93.

Cole, Jennifer. 1987. "Planar phonology and morphology." Ph.D. dissertation, MIT. [Published by Garland Press, New York, 1991.]

Cole, Jennifer and Loren Trigo. 1988. "Parasitic harmony." In Harry van der Hulst and Norval Smith (eds.), Features, segmental structure and harmony processes, pp.19-38. Dordrecht: Foris.

Dimmendaal, Gerrit. 1983. The Turkana language. Dordrecht: Foris.

Dimmendaal, Gerrit and Anneke Breedveld. 1986. "Tonal influence on vocalic quality." In Koen Bogers, Harry van der Hulst, and Maarten Mous (eds.), The Phonological Representation of Suprasegmentals, pp.1-33. Dordrecht: Foris.

Goldsmith, John. 1976. “Autosegmental phonology.” PhD. dissertation, MTT. [Published by Garland Press, New York, 1979.]

Goldsmith, John. 1990. Autosegmental and Metrical Phonology. New York: Blackwell.

Greenberg, Joseph. 1966. The Languages of Africa. The Hague: Mouton.

Halle, Morris. 1989. "The intrinsic structure of speech sounds." MIT, ms.

Halle, Morris. 1992. "Phonological features." In W. Bright (ed.), International Encyclopedia of Linguistics, Vol. 3, pp. 207-12. Oxford: Oxford University Press.

Inkelas, Sharon. 1994. "The consequences of optimization for underspecification." Proceedings of the Northeastern Linguistics Society 25: 287-302. 
Itô, Junko, Armin Mester, and Jaye Padgett. 1995. "Licensing and underspecification theory." Linguistic Inquiry 26: 571-613.

Kiparsky, Paul. 1981. "Vowel harmony.” MIT, ms.

Kiparsky, Paul. 1982. "Lexical morphology and phonology." In I.-S. Yang (ed.),Linguistics in the Morning Calm, pp. 3-91. Seoul: Hanshin.

Kiparsky, Paul. 1985. "Some consequences of lexical phonology." Phonology Yearbook 2:85-138.

McCarthy, John. 1979. "Formal problems in Semitic phonology and morphology." Ph.D. dissertation, MIT. [Published by Garland Press, New York, 1985.]

McCarthy, John and Alan Prince. 1993. "Prosodic morphology I." University of Massachusetts, Amherst and Rutgers University, ms.

Mohanan, K.P. 1991. "On the bases of radical underspecification." Natural Language and Linguistic Theory 9: 285-325.

Noske, Manuela 1990. "Vowel harmony in Turkana." Studies in the Linguistic Sciences 20: 123-34.

Noske, Manuela . 1991a. "Feature-changing harmony in Turkana." Proceedings of the Berkeley Linguistics Society 17: 166-76.

Noske, Manuela. 1991b. "Metrical structure and reduplication in Turkana." In M. Lionel Bender (ed.), Proceedings of the Fourth Nilo-Saharan Conference, pp. 245-62. Hamburg: Buske.

Noske, Manuela. 1993. "Tucano nasal harmony: Evidence for a ternary contrast in the feature Nasal." Proceedings of the Chicago Linguistic Society 29:311-28.

Prince, Alan and Paul Smolensky. 1993. "Optimality theory: Constraint interaction in generative grammar." Rutgers University and University of Colorado, Boulder, ms.

Ringen, Catherine. 1975. "Vowel harmony: Theoretical implications." Ph.D. dissertation, Indiana University. [Published by Garland Press, New York, 1988.] 
Ringen, Catherine. 1989. "Underspecification theory and binary features." In Harry van der Hulst and Norval Smith (eds.), Features, Segmental Stucture and Harmony Processes, pp. 145-69. Dordrecht: Foris.

Rottland, Franz and Laura A. Otaala. 1983. "Mid-vowel assimilation in TesoTurkana." In Rainer Vossen and Marianne Bechhaus-Gerst (eds.), Nilotic Studies 1, pp. 169-181. Berlin: Reimer.

Steriade, Donca. 1987. "Redundant values." Proceedings of the Chicago Linguistic Society 23: 339-62.

Steriade, Donca. 1995. "Underspecification and markedness." In John Goldsmith (ed.), The Handbook of Phonological Theory, pp. 114-74. New York: Blackwell.

Trigo, Loren. 1991. “On pharynx-larynx interaction." Phonology 8: 113-36.

Vossen, Rainer. 1982. The Eastern Nilotes. Berlin: Reimer.

Linguistics Program

University of California

Davis, CA 95616

mnoske@ucdavis.edu
[Received May 3, 1996;

provisional acceptance July 2,1996 ; final version accepted October 25, 1996] 
